\title{
THE NORMALITY OF INDUSTRIAL AND COMMERCIAL WASTE: ECONOMIC, TECHNICAL AND ORGANISATIONAL BARRIERS TO WASTE PREVENTION
}

\author{
Anette Svingstedt, Hervé Corvellec * and Emma Samsioe
}

Department of Service Studies, Lund University, Box 882, 25108 Helsingborg, Sweden
Article Info:
Received:
4 May 2020
Revised:
14 September 2020
Accepted:
30 September 2020
Available online:
28 December 2020
Keywords:
Waste prevention
Practice theory
Industrial waste
Commercial waste

\begin{abstract}
This study shows that the production of industrial and commercial waste should form part of normal organisational practices. When asked about waste prevention, representatives of food, textile, electronics and construction companies in Sweden have difficulties highlighting concrete waste-prevention objectives, measures and outcomes. Instead, they highlight economic, technical, and organisational barriers that prevent them from engaging in waste prevention, thereby endowing the production of waste with an economic, technical and organisational rationality. This triple rationalisation of waste production amounts to the managerial normalisation of waste that obstructs the implementation of waste prevention policies. Thus, we suggest that these policies aim to de-normalise industrial and commercial waste in similar ways to the measures used to de-normalise household waste.
\end{abstract}

\section{INTRODUCTION: WASTE PREVENTION - FROM PRIORITISED AREAS OF WASTE POL- ICY TO BUSINESS PRACTICES}

After decades of policy objectives, the question remains of how the goal of waste prevention should be achieved in practice. Waste prevention has long been a top priority in European waste policy. The importance of waste prevention was already mentioned in a European directive from 1975 (European Commission 75/442/EEC) and 1977 (European Commission 1977). These directives cited waste prevention as being a priority of waste management, ahead of reuse, material recycling and energy recovery. The Waste Framework Directive from 2008 (2008/98/EC) reconfirmed that the prevention of waste was the most important step in the waste hierarchy. The waste directive from 2018 (2018/851) also emphasised that "waste prevention is the most efficient way to improve resource efficiency and reduce the environmental impact of waste".

In light of these waste directives, it is important that Member States take appropriate measures to prevent waste generation, as is also demonstrated, for example, in Sweden's National Waste Plan 2011-2017. This emphasises that "waste prevention initiatives will also result in smaller quantities of hazardous substances in products and materials." (Swedish Environmental Protection Agency, 2012:28). Furthermore, waste prevention was already mentioned in the special national plan on for waste pre- vention for the period 2014-2017 (Swedish Environmental Protection Agency, 2015), and in the National Waste Plan for 2018-2023 (Swedish Environmental Protection Agency, 2018).

There is no shortage of individual waste prevention initiatives. This is demonstrated by the approx. 16,570 actions that The European Week for Waste Reduction (2019) listed in 2019. The purpose of these actions is to prevent the generation of waste. This includes providing information about the need to prevent waste, increase material efficiency and promote more sustainable consumption (Corvellec, 2016). However, apart from these pilot programmes, it is still not clear how waste-producing companies are working practices on waste prevention measures.

Previous research on waste prevention has primarily focused on household waste. For example, researchers have studied whether or not households should be controlled or supported in recycling more waste and reducing their household waste (Gregson et al., 2013; Corvellec \& Czarniawska, 2015; Corsini et al., 2018; Matsuda et al., 2018), particularly food waste (Setti et al., 2018; von Kameke \& Fischer, 2018). Researchers have also studied how laws, regulations and policies can be used as a means of control, primarily in households, in order to reduce household waste (Zacho \& Mosgaard, 2016; Johansson \& Corvellec, 2018).

It may seem odd that researchers have not focused on industrial and commercial waste, seeing that it is several
* Corresponding author

Hervé Corvellec

email: herve.corvellec@ism.lu.se
Detritus / Volume 13 - 2020 / pages 3-11

https://doi.org/10.31025/2611-4135/2020.14035

(C) 2020 Cisa Publisher. Open access article under CC BY-NC-ND license 
times larger in scale than household waste. The few examples of research in this field have focused on the ambiguous role of waste companies (De Jong \& Wolsink, 1997; Svingstedt \& Corvellec, 2018) or the limits of urban governance regarding waste prevention (Silva et.al., 2017; Hutner et al., 2017; Zapata Campos \& Zapata, 2017). Far less interest has been shown in how the companies that produce industrial and commercial waste perceive their opportunities to develop waste prevention practices, i.e. what organisations are doing in their day-to-day work to minimise the volume of waste produced, for example, through zero-waste manufacturing (Kerdlap et al., 2019).

Through the use of a practice theory approach (e.g. Reckwitz, 2002), the purpose of this article is to highlight and address the perceptions and practices of waste producers in the field of waste prevention. Greater knowledge of the perception and practices of producers will provide better conditions for proposing solutions to promoting waste prevention. We propose three unlocking measures that are fundamental to reducing the volume of industrial and commercial waste: making waste prevention more profitable, increasing knowledge of materials, and developing competence in the field of waste prevention.

This article is based on qualitative empirical material. Through a strategic selection of organisations in the four focus areas listed as priorities by the Swedish Environmental Protection Agency (2015) (food, textiles, electronics, construction and demolition), 26 interviews were conducted. Document analyses, focus group interviews and expert interviews were also conducted.

The article is structured as follows: First, there is a brief account of the practice theory approach, followed by a description of the qualitative method we used to collect and analyse our data. This is followed by a presentation of the respondents' descriptions of barriers (cf. De Jong \& Wolsink, 1997; Wilts et al. 2013; Bartl, 2014; Corvellec et al., 2013; Shahbazi et al., 2016; Aid et al., 2017) to waste prevention and also a discussion about the normality of waste generation (cf. O’Brien, 2008) and changing social practices to enable increased waste prevention.

\section{A PRACTICE THEORY APPROACH TO WASTE PREVENTION}

Practice theory focuses on what is done in organisations. It is not an individual theory but a collection of social theories that in different ways assume that people develop routines, habits and ways of doing and saying things in their daily lives - practices. Practice theory is used to understand social reality in all its richness, which is often difficult to interpret, sometimes with confusing contradictions. This is in stark contrast to the focus on structures, which is otherwise a common way of understanding and identifying solutions to the challenges faced by organisations.

In order to clarify what a practice is, we have applied the following, much-quoted, definition of a practice:

A 'practice' is a routinised type of behaviour which consists of several elements, interconnected to one other: forms of bodily activities, forms of mental activities, 'things' and their use, a background knowledge in the form of understanding, know-how, states of emotion and motivational knowledge. A practice is thus a routinised way in which bodies are moved, objects are handled, subjects are treated, things are described and the world is understood. (Reckwitz, 2002:250)

A practice comprises routinised activities that involve several different elements such as objects, body, knowledge and language which are interwoven with, and interdependent on, each other. There is a reciprocity that does not suggest one element over the others. Thus, a practice cannot be reduced to only one of these elements. A practice is always social in the sense that it is about a way of behaving and understanding one's reality that emerges in different places, at different times and with different people. Nor does the practice ever take place in isolation, but together with material objects and/or people and, in order to be a practice, it must be continuously reproduced by those who perform it (Shove \& Panzar, 2005).

In an effort to make it easier to study a practice that interweaves several different elements in interdependence, Shove and Pantzar (2005) argue that the practice involves actively integrating the elements of material, competence and meaning. The practice depends on a specific combination of these three elements (Shove et al., 2012). The first element, material, the hardware of practices, is of a more physical nature, such as an object: a tool, a technology or some other infrastructure (Hand et al., 2005; Shove et al., 2007). The human body, which through its bodily movements performs the practice, is also viewed as a kind of material.

The second element is the competence that people possess. Competence includes both knowledge in order to actually perform a task, and the knowledge that is required to be able to evaluate an achievement. Performing a practice also requires a kind of background understanding and know-how that is shared with others. Thus, people who take part in and perform a practice share an understanding of what is being said and done (Schatzki, 2001). To summarise, it is consequently a question of possessing practical competence and knowledge that enables you to actually perform a practice and understand what is happening in a practice. Taken together, these competences form the basis of the cognitive capacities that employees need to be able understand, engage in and actually perform the specific practice, for example - like this study - a waste prevention practice.

The third and final element involved in a practice is meaning or motivation. The fact that a practice creates meaning for those who perform it is a prerequisite for being able to reproduce it and thus maintain it over time. Meaning is partly about history and context (for example, this is what we do in this organisation), and a practice can also show that the organisation is forward-looking - there is a notion of the future of the practice (Shove et al., 2012). This means that when a practice is performed, it is both coloured by history and future-orientated.

In conclusion, the practice comprises and depends on material, competence and meaning, and if changes occur in any of these elements, the practice will also change 
(Hand et al., 2005). As a starting point, let us take a practice such as mobile shopping - a digital shopping practice that has emerged in recent years - to illustrate the reciprocity of the three practical elements (Fuentes, Bäckström \& Svingstedt, 2017; Fuentes \& Svingstedt, 2017). The practice of mobile shopping relies on a technical device, a mobile phone, which consumers use for mobile shopping. The consumer needs a certain level of digital competence in order to shop using their mobile phones, as well as competence that they develop through digital tutorials, chat groups and social media. This enables them to use their mobile phones seamlessly and efficiently when shopping. Mobile shopping has meaning because consumers experience greater independence, as they can control how, where and when they shop. The same applies to practices relating to waste prevention apps, which aim to encourage people to repair their products instead of buy new products, or apps that enable them to find restaurants and shops selling leftover food at a discounted price.

The three practical elements cannot be separated, they are interwoven to the point that they both assume and constitute each other (Shove \& Pantzar, 2005). A dynamic combination of material, competence and meaning are necessary in order to make everyday life work.

By applying a practice theory perspective to waste prevention, we provide the basi for an understanding of prevention based on what is being said and done - or not. It becomes a way of understanding and conceptualising prevention as one social practice among other social practices that exist in organisations. In other words, a practice theory approach offers both an everyday and a theoretically substantiated understanding of waste prevention.

\section{METHOD:DATA COLLECTION AND ANALYSIS}

This study is based on a qualitative study of organisations in Sweden that are active in the four focus areas listed as priorities by the Swedish Environmental Protection Agency (2015) in Sweden's waste prevention programme. The collection of empirical material was undertaken in two phases, while the analysis was undertaken on an ongoing basis.

Before the first phase, we conducted a systematic search of a number of Swedish industry journals in order to identify organisations acknowledged as having an interest in, or that worked with, waste prevention. These organisations were contacted and asked whether they would like to participate in interviews. During the interviews, we asked for additional tips on other actors who they felt could be included in the study. This is known as a snowball selection (Silverman, 2004).

The collection of empirical material in the first phase was undertaken through 26 individual interviews with sustainability managers, purchasing managers, regional managers or quality and environmental managers: six respondents from the food sector (food organisations, food cooperatives, food wholesalers and municipalities), six from the textile sector (fashion chains, design brands and a textile collection organisation), seven from the electronics sector, (sellers of products such as computers, computer accessories, appliances, household appliances and organisations that are major consumers of computers and computer accessories, as well as organisations dealing with the reuse of computers, and municipalities that undertake extensive purchasing of computers are also included in this category), six from the construction and demolition sector (construction and property organisations). In addition, one interviewee represented an organisation that is active in the sanitation industry.

Seven of the interviews were conducted on site, while 19 were conducted over the phone. The interviews were structured on the basis of a prepared interview guide with a number of specified questions addressing topics such as barriers and opportunities in work on waste prevention, and the circular economy (see Table 1 for examples of questions). We adopted a reflective approach to the qualitative interview (Holstein \& Gubrium, 1995), using this to investigate how the respondents perceived waste prevention in their respective organisations, described problems and barriers and discussed the way in which they addressed waste prevention and, in purely practical terms, reduced industrial and commercial waste. The sequence of questions changed after the first five interviews as the respondents tended to become focused on descriptions of their "success stories", leaving less scope for subsequent questions about problems and perceived barriers. Following this change of sequence, the interviews focused more on the barriers and challenges that waste prevention can entail.

Supplementary data were retrieved in documents such as European Directives (2008/98; 2018/851), Swedish waste plans (Swedish Environmental Protection Agency, 2012, 2018) and waste prevention programmes (Swedish Environmental Protection Agency, 2015).

The second phase of collection of empirical material was based on three focus group interviews and expert interviews. Two of the focus groups involved representatives of the food, textile and electronics sectors, as well as the construction and demolition sector, and one group involved representatives of the project's reference companies. The interviews were conducted via Skype, lasted for around 45 minutes, and were recorded and transcribed verbatim. On these occasions, and interview guide was used as a basis with questions about how a company could work to reduce waste or be more resource or material efficient (see Table 2).

We also collected material via four individual expert interviews with people who had extensive experience of working with waste prevention in areas such as textiles and construction and demolition, as well as policy analysis and environmental investigations. The purpose of these interviews was to validate our preliminary results from phase one and parts of phase two (see Table 3 ).

TABLE 1: Examples of questions in the individual interviews

What experience do you have of problems or barriers in your work on waste prevention?

What kind of measures would you like to see from the state/government agencies/industry associations to contribute to increased waste prevention?

How do you work with waste prevention and in what ways are you encouraged to do more of this work? 
TABLE 2: Examples of questions in the focus group interviews.

How do our results appear in relation to your knowledge and experience of waste prevention?

Do you recognise these barriers or have you seen other barriers than those we have identified?

Do you have any other comments or views about the contents of the report?

TABLE 3: Examples of questions in the expert interviews.

What barriers do you see for work on waste prevention?

How are you currently working with waste prevention?

Analysis of the material collected was undertaken on an ongoing basis. Phase one identified the fact that the respondents highlighted three main barriers to waste prevention: commercial, technical and organisational. The quality of this classification was validated via the focus group interviews in phase two. In addition, the material that was collected on each of the three main barriers identified in phase 1 was coded based on the three types of practice elements to which Shove and Pantzar (2005) refer: material, competence and motivation. This coding was conducted based on an effort to explain why work on waste prevention is being prevented hindered or enabled by commercial, technical and organisational practices. Phase two also used a number of expert interviews to validate the analysis of waste prevention practices conducted in both phase one and two. These expert interviews resulted in certain observations being refined, which led to findings to the effect that the production of waste is the norm for companies, while waste prevention remains something that is vague, relatively alien.

\section{BARRIERS AND SOCIAL PRACTICES THAT MAKE WASTE PREVENTION MORE DIFFI- CULT}

This section presents the respondents' descriptions of three kinds of barriers to increased waste prevention and the social practices behind them. The first is a commercial barrier, which stems from the fact that it costs more to prevent waste than to produce and manage waste. The second barrier is the lack of technical solutions and/or conditions for preventing at least certain kinds of waste. The third barrier is organisational barriers, for example, that established norms and values lean more towards producing waste than preventing the generation of waste. The technical and economic barriers to waste prevention by public bodies identified by Wilts et al. (2013) can be recognised in these three barriers, as well as some of the technological, economic, organisational, as well as legal, informational and social barriers to material efficiency in manufacturing identified by Shahbazi et al. (2016), and the economic, social, technological, information-related, and policy-related barriers to inter-organisational waste management identified by Aid et al. (2017).

What is interesting about these barriers and the practices related to them is that not only do they provide an under- standing of the lock-ins (Corvellec et al., 2013; Svingstedt \& Corvellec, 2018) that prevent waste prevention according to the producers of industrial and commercial waste. They also indicate what waste producers could do to start working on waste prevention. Practices that obstruct waste prevention of industrial and commercial waste explain, albeit in reverse, the practices that are being developed in order to reduce and also prevent the generation of waste.

The way that the respondents chose to express themselves in the interviews should be understood in light of the fact that the subject of waste prevention can be sensitive. There may be a need to depict their organisation as a waste prevention organisation. Many of the respondents have a responsibility for working in such a way and would want to defend and portray their organisation's waste prevention work on waste in an overly positive way when we asked critical questions. This is a common example of what is known as the interviewer effect (Silverman, 2004).

\subsection{Commercial barriers}

Interviewees from all four areas emphasised the key importance of delivering a good financial result. As one of the experts stated: It is the commercial perspective that dominates the other barriers (Expert 1). The central role from the commercial perspective assumes different forms. For some organisations, it is a challenge to match purchases and sales to minimise leftovers:

/.../leftovers, that's really our biggest headache I'd say, because it's both an environmental issue and an economic issue. Of course, it's about all this material that is left lying on a shelf. It has a value, after all; we've paid for it. It really is in our interest that it is used. And, of course, there's an environmental impact if you produce something that you don't actually need and is ultimately just thrown away. (Sustainability Manager, textiles)

The optimisation of matching between purchases and sales is a waste prevention practice that is perceived as meaningful by employees because it is focused on reducing costs and increasing efficiency. Cost awareness of waste prevention regarding industrial and commercial waste is evident along the entire value chain.

Another example of how finances control waste practices is an accepted way that the construction sector orders timber products. This takes place on several levels by different actors in the production chain. It usually results in all actors at all levels placing slightly larger orders than are needed in order to avoid causing a halt in production. There is a deeply-rooted cultural awareness in the construction sector that whenever a construction project is halted, major costs are generated.

It is a cultural issue, which people have become used to. Input products cost less in relation to labour and other costs, so sometimes you order a little extra just in case, which naturally results in an increase in the volume of waste. (Sustainability Manager, construction and demolition).

A well-established practice, involving competences and procedures that have been developed over the years, is to to ensure that time is saved on projects, while overlooking 
the relevance of saving on waste. The cost of handling construction waste is so minimal that it plays less of a role in large construction projects (Svingstedt \& Corvellec, 2018), as was also confirmed in an expert interview:

We also noted that waste is considered cheap in the construction sector. The costs associated with construction waste are negligible. (Expert 2)

The relatively low cost of waste and its management contributes to giving the issue of waste a low status and a priority that is difficult for employees to find meaningful.

Conversely, a higher cost of waste increases the interest in waste prevention. If waste in the construction sector is about goods with low value added, waste in the clothing industry is about goods that are ready to be sold and are therefore significantly more expensive. It costs an organisation not to sell a textile product. The production of waste is then regarded as a problem, the cost of which must be reduced. A product that is not sold remains the responsibility of the organisation, something they must pay to dispose of.

A common key driver for many of the organisations in the prevention of industrial and commercial waste is the relative cost of what is thrown away in relation to how much it costs to dispose of it. The production of waste appears to be the result of a commercial balance between, on the one hand, the cost of the material and the degree of processing what is being discarded and, on the other hand, what is required to manage the waste in relation to the costs of any additional work and interruptions to production. Consequently, increased resource efficiency that may result from waste prevention practices is developed not through caring for the environment, but rather by a managerial calculation.

\subsection{Technical barriers}

Technical barriers are about difficulties in developing, finding and using technical solutions that can reduce waste. When it comes to technical barriers, finances must also be taken into account. Respondents put technical solutions in relation to their costs. What they are able to engage in is usually governed by the costs associated with testing technological innovations.

One Sustainability Manager for a major fashion organisation described how the organisation was participating in a project in which it was testing the prototype production of clothing produced from materials that can be recycled through the separation of fibre:

But to be perfectly honest, there's a great deal of manual tweaking and individual handling when you're manufacturing prototypes. It wouldn't have worked to produce a lot, not even 1,000 garments, which is what we'd need to produce in order to put these on the market. So, this is more like a pilot study. However, it is certainly not commercially viable yet, unfortunately (comment: spring 2018), although we thought it might be in 2013. (Sustainability Manager, textiles)

Within the organisation, people are aware that it is not possible to create technical solutions that work and generate financial returns with immediate effect. However, they are not prepared to bear the development costs that are required for full-scale production.

Innovation is seen as a way of developing the organisation's knowledge base and know-how in order to understand the technical requirements:

At first I thought it was mainly a matter of learning 'what's it all about? What kind of opportunities are there? What are the opportunities for collaboration that maybe don't exist today? (Sustainability Manager, textiles)

Waste prevention practices are something that must be tested, developed, implemented in the operational organisation, accepted by others and developed further. However, at present, the technology (materials), know-how (competence) and motivation (meaning) do not exist for this to become a fully sustainable technology (Shove et al., 2012). The technology is lacking to some extent, making it difficult for new waste prevention practices to be developed. In textiles, technological innovations often require collaboration throughout the entire supply chain. Collaboration with other actors to take part of innovations appearing, for exemple, among suppliers. This means that, in the textile organisation, there is no change in the day-to-day practices. Many respondents also believed that responsibility for prevention rests with other actors, outside their own organisation. They wanted to believe that other, larger actors would assume responsibility for development.

Currently, it's not really clear what you're supposed to do when you recycle textiles; it's quite complicated. We're too small and don't have sufficient resources to take a lead in that kind of development, but we try to keep up and see what is happening". (Sustainability Manager, textiles)

Development is expected to take place primarily outside the business's own organisation or by identifying ways of collaborating with other actors in the supply chain.

The same kind of hope for future technological development was expressed by our respondents in the food industry. A current problem with many food packaging items is that they are designed on the basis that there should be larger packaging items for multi-person households, even though many households in Sweden are small, which increases the risk of food waste, even if it also reduces packaging waste per unit of weight or volume. However, changing the size of packaging involves costs, as a Sustainability Manager in the food industry reminded us:

It's always the case in the food industry that you try to minimise packaging solutions, while at the same time that you have invested in a packaging line, so you're rather stuck for a while. It's quite expensive to change - you don't change the size of the packaging every day. (Sustainability Manager, food)

Here, as is so often the case, it is a combination of economic and technical factors that lock practices into packaging solutions that risk entailing increased food waste. New practices are difficult when both technology, and to some extent competence, are lacking, although there does seem to be some motivation for change. 
Apart from a general hope for technical solutions, respondents in all areas described an interested but cautious approach to the introduction of waste preventing innovations. Some respondent stated that they had tested a number of innovative solutions on a smaller scale, but did not express any ambition to invest in the development of new and more effective waste prevention technologies. Becoming involved in innovation projects to test different solutions or to invest in some form of technical aid is considered both unsafe and risky. There is still a lack of technology for new and more effective waste prevention practices.

\subsection{Organisational barriers}

The respondents also experienced different forms of organisational barriers, procedures and practices in their work on waste prevention, which, according to the respondents, indirectly affected waste prevention in the organisations they represented. These have been created over time, are part of everyday work and contributed to the organisation producing more waste than necessary. Organisationally, the production of waste represented normal practice, and not to do so would then become abnormal.

The respondents were aware that some organisational procedures generate more waste than necessary. There is an understanding that changes are needed in work methods and that such changes are based on a mindset that says this is the way we've always done it - it is about habitual ways of thinking, ways that create meaning for employees. One purchasing manager in the electronics sector believed that a culture has developed that makes work on waste prevention more difficult:

Every department that has purchased a phone also owns this phone, even though we have services in which we receive end-of-life equipment that takes care of this. So we haven't really purchased equipment that we want. It's probably the organisational culture, which has always believed that you should keep owning your own hardware. (Purchasing Manager, electronics)

This quote makes it clear that the organisational culture obstructs practices directed towards waste prevention.

Other organisational barriers are a lack of control and influence over the production of waste by other actors in the supply chain. The respondents were aware that waste was produced at every stage of the value chain, while at the same time they felt that their organisation did not have sufficient insight into other stages of the value chain and was therefore unable to influence these parts. They only controlled their own stage, which limits what they can do to reduce the generation of waste. Regarding systems for collecting used clothes and textiles, for example, one regional manager in a textile company stated:

Whether or not a consumer wants to pass on, throw away or burn garments, is left to chance. It's up to the consumer and the collector can also largely do whatever they want. /.../ A lot is left to the interests of individual actors. (Regional Manager, textiles).
Existing practices do not consider the whole production process, and there is therefore neither insight into nor the opportunity to control the processes of other actors that generate waste.

From conversations with the respondents, it is also evident that organisations are not always organised to work on waste prevention. In turn, this results in organisations tending to look to other actors, both inside and outside the value chain, in the hope that they will be organised to deal with the generation of waste.

This study indicates a wide range of social practices that prevent the way of the increased prevention of industrial and commercial waste, based on how the organisation of work and material flows is conducted. Taken together, all of the barriers we have identified represent major challenges for increased waste prevention. Our respondents described costs, technology and ingrained work methods as effectively putting a brake on the prevention of industrial and commercial waste. Legal, informational and institutional barriers (Wilts et al., 2013; Shahbazi et al., 2016) are additional factors. At the same time, these barriers also highlight potential ways of moving forward with the issue.

\section{DISCUSSION: CHANGING SOCIAL PRAC- TICES FOR INCREASED WASTE PREVENTION}

The previous section showed how respondents approached the daily practices of waste prevention. They mainly described the barriers and practices that challenge their work on waste prevention.

Several structural impediments to waste prevention have been identified in the literature. Based on the Dutch case, De Jong and Wolsink (1997) have highlighted the entwining of interests of municipal and regional authorities in waste collection and waste disposal. They also suggest that it is in the interests of private collecting organisations to keep governmental policymakers in a situation of uncertainty about the volume and type of waste that will be released in order to avoid the formulation of a deliberate waste policy. Looking at the European Union, Bartl (2014) lists several barriers to waste prevention: a conflict of interests between reducing the quantity of waste and therefore the amount of materials that have to be processed, and securing the turnaround and profit of waste collectors, recyclers, waste to energy facilities, and landfill operators; the absence of decoupling waste generation from economic growth; unclear measurement of waste prevention; the interest of producers and retailers in increasing production and sales that go against extending the life span of products; producers' lack of interest in reusing; the export of waste that shifts the waste burden from one country to another.

Adopting a managerial rather than a structural perspective, our respondents stated that waste prevention is hampered by a narrow, commercial view of waste-related income and expenses, a lack of technical solutions, and organisational standards that are not based on preventing the generation of waste. These economic, technical and organisational barriers overlap with the institutional, technical, cultural and material lock-ins identified by Corvellec 
et al. (2013) in waste management infrastructures. They discourage any change in the social practices of the organisational management of waste in order to promote waste prevention.

When the respondents offered their managerial views on waste prevention, they primarily talked about what they were doing or would like to do in terms of recycling, despite the fact that the waste hierarchy $(2008 / 98 / E C)$ clearly distinguishes between prevention and recycling. The fact that the interviewees chose to talk about recycling when asked about waste prevention shows that even though the general principle of the waste hierarchy is known, the understanding of the technical specifications that characterise its various stages is more vague.

In terms of Shove and Pantzar's (2005) practice theory, firstly, the commercial barriers imply motivation, technical barriers imply materiality, and organisational barriers imply competence. This study shows that the gap between policy goals, the ambitions for increased waste prevention and what is actually being done is explained by the fact that the respondents lack motivation, material solutions and competence to develop practices that focuses on reducing waste. What characterises a practice is that the different elements are interwoven and interact, which makes it difficult to isolate one individual element. In the three barriers we have identified, it is important how the different practice elements interrelate.

Material - the hardware of practice - is a prerequisite for being able to perform a social practice (Shove et al., 2012). The study shows that technology, technical support systems are either lacking or inadequate for managing waste prevention. The available technology aimed at reducing waste volumes does not meet the financial criteria defined by the organisations. When finances do not permit the development of new technology, and the technology that does exist is not suitable for contributing to waste reduction, it is difficult to create the motivation to change waste practices. The conditions to constitute a social practice aimed at increased waste prevention do not exist. Modern technology shapes a social practice that is focused on waste production. New hardware is needed, as well as new technological solutions, which are also likely to require other types of business models in order to encourage change.

Competence is the second practice element involved in a social practice. This is about both knowledge in order to work in purely practical terms on waste prevention measures and also to evaluate such measures. This study shows that there is reliable information, based on a traditional commercial approach, of how profitability is created. The respondents share an understanding of how products are produced that do indeed generate waste, with the least amount of time wasted. Also, the basic view is that reducing waste is usually not worthwhile, and there is a lack of competence in how reducing waste can be made economically viable. The practice is based on norms and values that describe how to deal with the waste that is generated (cf. Corsini et al, 2018, but for households). Attempts made to change the norms in organisations are primarily about making it more natural to increase the level of recycling or reuse, and not reduce waste per se. An organisational change in norms is needed that helps make it more natural to reduce waste than to produce it.

There must be motivation or meaning - the third and final element that constitutes a practice - in doing what you do. Employees must have a common understanding of the existing practice (Reckwitz, 2002). This study shows that it is meaningful for respondents to have a practice that follows a strict commercial approach to the organisation's waste production. There is, however, no justification for reducing waste, as such a practice may increase the organisation's costs. Current production technology creates meaning by offering what is needed to make its production efficient from a strictly economic perspective. Thus, it is difficult to create the motivation for potential technological development. Organisational values, norms and procedures are based on the production of waste being viewed as natural. On the other hand, it is not meaningful to have practices that focus on waste prevention.

The social practices in the respondents' organisations are not structured for managing waste prevention. There is no available waste prevention technology, there is a low level of competence in waste prevention, and there is no motivation to reduce organisational waste. The normal, everyday social practice in these organisations is to produce waste, not to prevent it from being generated. It is true that waste is equated with the destruction of resources, a kind of wastage that should be limited. Nonetheless, our respondents normalised the production of waste on the grounds that it was commercially justifiable, and also technically and organisationally unavoidable.

As one of the reviewers stated, the respondents provide an example here of what O'Brien (2008, p. 178) calls the paradox of waste: an ability to "simultaneously express value and non-value". They regard waste production as the destruction of value, yet a constituent feature of their business logic of profit-making (cf. Svingstedt, 2012). For them, waste is troubling and regrettable, yet it is the normal consequence of prioritised practices such as delivering on time, monitoring technical developments, offering a wide product range or driving down costs.

Conversely, with the exception of representatives of organisations that have made waste prevention their business concept, the respondents stated that they lacked the motivation, material opportunities and organisational competence to develop waste prevention practices.

Despite decades of political priorities, waste prevention is still an issue that appears to be unclear, uncertain, supposedly difficult, and almost in conflict with the organisation's interests. What appears to be a logical waste policy goal based on the waste hierarchy - that it is better to prevent waste than to have to manage it - seems odd when the everyday practices of waste producers are considered. It is part of the normality of businesses to combat the generation of waste, but only to the point where it is no longer organisationally, technically and economically justifiable.

The waste policy goals of preventing waste generation become stranded in the organisation's everyday practices. This explains why waste volumes continue to grow, despite decades of prioritisation. These goals do not recognise the fact that organisational members have adopted a mindset 
that views waste production as a normal outcome of organisational activities. While waste is seen as a problem for politicians - such as a risk to public health, an environmental hazard or the waste of resources - waste producers see industrial and commercial waste as something that is inevitable, rational and justifiable. The waste practices of the waste-producing organisations whose representatives we met were not orientated towards reducing waste production. In order to change the practices, a paradigm shift is needed that denormalises waste production and let waste prevention take precedence over, for example, profitability.

\section{CONCLUSIONS AND SUGGESTED UNLOCK- ING MEASURES}

Based on a qualitative interview-based study with representatives of Swedish organisations in the textile, construction and demolition, food and electronics sectors, this study has identified three barriers that aggravate waste prevention: a commercial approach that regards waste as an economic balance, an absence of reasonable technical solutions, and organisational habits and procedures that are not directed towards prevention. These barriers give rise to everyday social practices that are not geared towards the prevention of industrial and commercial waste: there is neither the technology, the competence nor the motivation for a social practice that prevents waste.

We find that the production of waste is seen as a normal practice: the norm, an inevitable consequence of the business' existence, even though efforts are being made to reduce waste as long as it is economically sound, organisationally acceptable, and technically feasible. Our study demonstrates what we call the normality of waste, and, in contradistinction, the oddity of waste prevention. Our results show a lack of businesses relevance of waste prevention. We therefore suggest that in order to make waste prevention objectives relevant, there is a need for financial motivation, knowledge of materials, and the competence to prevent industrial and commercial waste.

A final question is whether or not a transition to a circular economy creates the opportunity to work on waste prevention, as several of our respondents have speculated. The circular economy is portrayed by its advocates as a way of designing out waste (Ellen MacArthur Foundation 2017). However, firstly, this requires the circular economy to aim beyond an increase in the use of recycled materials and waste recycling, and start relating waste to consumption (e.g. European Parliament 2018). Secondly, there is a need to create an acceptance of and demand for circular innovations (Cainelli, D'Amato \& Mazzanti, 2020). In practice, it would appear that getting suppliers, business partners and customers to assume the risk and perhaps also the cost of stopping material flows is a significant challenge, particularly for small businesses that only control a small part of their value chain, and which also lack the ability to change market standards on their own (see, Corvellec, Babri \& Stål, Forthcoming 2020). Thirdly, the current linear solutions, with which circular innovations are usually compared, must also be made expensive and unattractive. Above all, the circular economy must not function as a way to divert attention away from the need to try to develop lowwaste practices right now.

\section{ACKNOWLEDGEMENTS}

This study is part of the research project Preventing Industrial and Commercial Waste - Locking and Unlocking Measures, funded by the Re:Source programme and the Swedish Energy Agency (Project number 44087-1.) We would like to express our gratitude to our respondents for giving us their time, particularly the members of the reference group: Elin Trossholmen (Stena Recycling AB), Peter Johansson (Svensk Avfallsrådgivning), and Kim Olsson (NSR). We are also grateful to Patrik Zapata (University of Gothenburg), and Nils Johansson (KTH Royal Institute of Technology), for their comments about a previous version of this text.

\section{REFERENCES}

Aid, G., Eklund, M., Anderberg, S., Baas, L. (2017). Expanding roles for the Swedish waste management sector in inter-organizational resource management. Resources, Conservation and Recycling, 124 (Supplement C), 85-97. https://doi.org/10.1016/j.resconrec.2017.04.007

Bartl, A., 2014. Moving from recycling to waste prevention: A review of barriers and enables. Waste Management \& Research, 32 (9 suppl), 3-18. https://doi.org/10.1177/0734242X14541986

Cainelli, G., D’Amato, A., Mazzanti, M., 2020. Resource efficient eco-innovations for a circular economy: Evidence from EU firms. Research Policy, 49, 103-827. https://doi.org/10.1016/j.respol.2019.103827

Corsini, F., Gusmerotti, N. M., Testa, F., Iraldo, F., 2018. Exploring waste prevention behaviour through empirical research. Waste Management, 79, 132-141. https://doi.org/10.1016/j.wasman.2018.07.037

Corvellec, H., 2016. A performative definition of waste prevention. Waste Management, 52, 3-13. http://dx.doi.org/10.1016/j.wasman.2016.03.051

Corvellec, H., Babri, M., Stål, M., Forthcoming. Putting circular ambitions into action: The case of Accus, a small Swedish sign company. In M. Brandão, D. Lazarevic \& G. Finnveden (eds.), Handbook of the circular economy, pp: n.a., Cheltenham: Edward Elgar. ISBN: n.a.

Corvellec, H., Czarniawska, B., 2015. Action nets for waste prevention. In Waste management and sustainable consumption: Reflection on consumer waste. In K.M., Ekström (ed.), pp: 88-101. Oxford: Earthscan-Routledge.

Corvellec, H., Zapata Campos, MJ., Zapata, P., 2013. Infrastructures, Lock -in, and Sustainable Urban Development - The Case of Waste Incineration in the Göteborg Metropolitan Area. Journal of Cleaner Production, 1(50), 32-39.https://doi.org/10.1016/j.jclepro.2012.12.009

de Jong, P., Wolsink, M., 1997. The structure of the Dutch waste sector and impediments for waste reduction. Waste Management \& Research 15(6): 641-658. https://doi.org/10.1177/0734242X9701500608

Ellen MacArthur Foundation, 2017. Concept. Cowes: Ellen MacArthur Foundation. https://www.ellenmacarthurfoundation.org/circular-economy/overview/concept (Access date : 4 May, 2020)

European Commission, 75/442/EEC. Waste directive. Official Journal of the European Union, 194.

European Commission, 1977. 2nd Environmental Action Programme 1977-1981. Official Journal of the European Union - C, 139 (13.6.77).

European Parliament, 2018. Circular economy: More recycling of household waste, less landfilling Brussels: European Parliament.

Fuentes, C., Bäckström, K., Svingstedt, A., 2017. Smartphones and the reconfiguration of retailscapes: Stores, shopping, and digitalization. Journal of Retailing and Consumer Services, 39, 270-278. https://doi.org/10.1016/j.jretconser.2017.08.006

Fuentes, C., Svingstedt, A., 2017. Mobile phones and the practice of shopping: a study of how young adults use smartphones to shop. Journal of Retailing and Consumer Services, 38, 137-146. https:// doi.org/10.1016/j.jretconser.2017.06.002 
Gregson, N., M. Crang, J. Laws, T. Fleetwood, H. Holmes., 2013. Moving up the waste hierarchy: Car boot sales, reuse exchange and the challenges of consumer culture to waste prevention. Resources, Conservation and Recycling, 77(0), 97-107. http://dx.doi. org/10.1016/j.resconrec.2013.06.005

Hand, M., Shove, E., Southerton, D., 2005. Explaining showering: A discussion of the material, conventional, and temporal dimension. Sociological Research Online, 10(2). https://doi.org/10.5153/ sro. 1100

Holsteain, J.A., Gubrium J.F., 1995. The active interview. London: Sage. ISBN: 0-8039-5895-1

Hutner, P., Thorenz, A., Tuma, A. (2017). Waste prevention in communities: A comprehensive survey analyzing status quo, potentials, barriers and measures. Journal of Cleaner Production, 141, 837-851. http://dx.doi.org/10.1016/j.jclepro.2016.09.156

Johansson, N., Corvellec, H., 2018. Waste policies gone soft: An analysis of European and Swedish waste prevention plans. Waste Management, 77, 322-332. https://doi.org/10.1016/j.wasman.2018.04.015

Kerdlap, P., Low, J.S.C., Ramakrishna, S. (2019). Zero waste manufacturing: A framework and review of technology, research, and implementation barriers for enabling a circular economy transition in Singapore. Resources, Conservation and Recycling, 151, 104438. https://doi.org/10.1016/j.resconrec.2019.104438

Matsuda, T., Hirai, Y., Asari, M., Yano, J., Miura, T., Ii, R., Sakai, S.-I., (2018). Monitoring environmental burden reduction from household waste prevention. Waste Management, 71, 2-9. https://doi. org/10.1016/j.wasman.2017.10.014

Naturvårdsverket, 2015. Tillsammans vinner vi på ett giftfritt och resurseffektivt samhälle: Sveriges program för att förebygga avfall 2014-2017, Stockholm: Naturvårdsverket.

Naturvårdsverket, 2018. Att göra mer med mindre: Sveriges avfallsplan och avfallsförebyggande program 2018-2023 (Rapport 6857). Stockholm: Naturvårdsverket.

O'Brien, M. (2008). A crisis of waste?: Understanding the rubbish society. New York: Routledge. ISBN: 978-0-415-96098-4

Reckwitz, A., 2002. Toward a theory of social practices: A development in culturalist theory. European Journal of Social Theory, 5(2), 243263. https://doi.org/10.1177/13684310222225432

Schatzki, T. R., 2001. Introduction: Practice theory. In T. R. Schatzki, K. Knorr-Cetina, \& E. v. Savigny (ed.), The practice turn in contemporary theory, pp: 1-14. London: Routledge. ISBN: 0-415-22814-X

Setti, M., Banchelli, F., Falasconi, L., Segrè, A., Vittuari, M., 2018. Consumers' food cycle and household waste. When behaviors matter. Journal of Cleaner Production, 185, 694-706. https://doi. org/10.1016/j.jclepro.2018.03.024
Shahbazi, S., Wiktorsson, M., Kurdve, M., Jönsson, C., \& Bjelkemyr, M. (2016). Material efficiency in manufacturing: Swedish evidence on potential, barriers and strategies. Journal of Cleaner Production, 127, 438-450. http://dx.doi.org/10.1016/j.jclepro.2016.03.143

Shove, E., Pantzar, M., 2005. Consumers, producers and practices: Understanding the invention and reinvention of Nordic walking. Journal of Consumer Culture, 5(1), 43-64. https://doi. org/10.1177/1469540505049846

Shove, E., Pantzar, M., Watson, M., 2012. The dynamics of social practice: Everyday life and how it changes. London: Sage. ISBN: 9780-85702-043-7

Shove, E., Watson, M., Hand, M., Ingram, J., 2007. The design of everyday life. Oxford: Berg. ISBN: 1-84520-682-7

Silva, A., Rosano, M., Stocker, L., Gorissen, L., 2017. From waste to sustainable materials management: Three case studies of the transition journey. Waste Management, 61(Supplement C), 547-557. https://doi.org/10.1016/j.wasman.2016.11.038

Silverman, D. 2004. Qualitative research: Issues of theory, method and practice. Second edition. London: SAGE. ISBN: 0-7619-4934-8

Svingstedt, A. 2012. Servicemötets praktik: På en tingsrätt, ett äldreboende och ett hotell. Lund: Lunds universitet, Institutionen för Service Management. ISBN: 978-91-7473-378-5

Svingstedt, A., Corvellec, H. 2018., When lock-ins impede value co-creation in services. International Journal of Quality and Service Sciences, 10(1), 2-15. https://doi.org/10.1108/ IJQSS-10-2016-0072

Swedish Environmental Protection Agency (2012) From waste management to resource efficiency: Sweden's waste plan 2012-2017. Stockholm: Naturvårdsverket.

The European Week for Waste Reduction, 2019. The project, http:// www.ewwr.eu/en/project/main-features (Retrieved 2019-11-01)

von Kameke, C., Fischer, D., 2018. Preventing household food waste via nudging: An exploration of consumer perceptions. Journal of Cleaner Production, 184, 32-40. https://doi.org/10.1016/j.jclepro.2018.02.131

Wilts, H., Dehoust, G., Jepsen, D., Knappe, F. (2013). Eco-innovations for waste prevention: Best practices, drivers and barriers. Science of the Total Environment, 461-462(0), 823-829. doi:http://dx.doi. org/10.1016/j.scitotenv.2013.05.096

Zacho, K.O., Mosgaard M.A., 2016. Understanding the role of waste prevention in local waste management: A literature review. Waste Management \& Research, 34(10), 980-994. https://doi. org/10.1177/0734242X16652958

Zapata Campos, M. J., Zapata, P., 2017. Infiltrating citizen-driven initiatives for sustainability. Environmental Politics, 26(6), 1055-1078. https://doi.org/10.1080/09644016.2017.1352592 